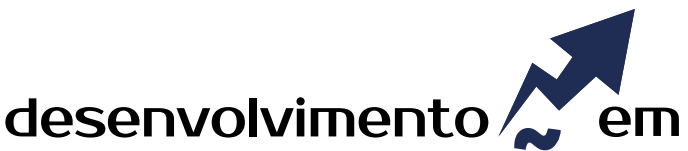 QUESTÃO
}

\section{O Desenvolvimento Baseado em Conhecimento no Contexto das Cidades: Uma Análise do Caso de Monterrey}

http://dx.doi.org/10.21527/2237-6453.2019.46.249-267

Recebido em: 3/8/2017

Aceito em: $17 / 8 / 2018$

\author{
Fernanda Rizzon ${ }^{1}$, Ana Cristina Fachinelli ${ }^{2}$, Mayara Pires Zanotto ${ }^{3}$, \\ Misael Paulo Montaña ${ }^{4}$, Edson Fontana da Silva ${ }^{5}$
}

\begin{abstract}
RESUMO
Conforme a economia migrou de essencialmente agrícola para industrial e comercial, acompanhada do aumento populacional, surgiram as cidades como modelo inicial de sistema de organização humana e econômica. Nos dias atuais emergem os conceitos de Cidade do Conhecimento, pois as cidades não são mais vistas exclusivamente como centros econômico-financeiros, mas como um conjunto de valores tangíveis e intangíveis que se relacionam com pessoas, empresas e governos em uma tríplice hélice. Com o objetivo de examinar a aplicação do conceito de Cidade do Conhecimento, este artigo apresenta um estudo de caso único tendo como objeto de estudo a cidade mexicana de Monterrey, considerada uma cidade do conhecimento emergente. $\mathrm{O}$ caso de Monterrey revela oportunidades balizadas pela sociedade do conhecimento, uma vez que esta requer a mobilização de recursos endógenos, assim como os exemplos observados nesse artigo nos apresentam o fato de que os recursos do conhecimento já existem e possuem uma espécie de "enraizamento" em valores culturais e históricos, desenvolvidos de forma orgânica e única. Quanto às limitações do estudo, é importante considerar o recorte temporal restrito aos anos 2008 e 2009, o que limitou a análise do caso em relação a fatos mais recentes, tais como a instalação de cartéis de narcotráfico na cidade que abalaram seus planos e estratégias. Esses fatos recentes representam uma perspectiva para a continuação do estudo do caso de Monterrey orientado para a análise dos impactos da violência e da criminalidade organizada no seu sistema de capitais.
\end{abstract}

Palavras-chave: Cidades do conhecimento. Monterrey. Estudo de caso.

KNOWLEDGE-BASED DEVELOPMENT IN THE CONTEXT OF CITIES: AN ANALISYS OF THE CASE OF MONTERREY

\section{ABSTRACT}

As the economy migrated from essentially agricultural to industrial and commercial, accompanied by population growth, cities emerged as the initial model of a system of human and economic organization. Nowadays, the concepts of City of Knowledge emerge, since cities are no longer seen exclusively as economic-financial centers, but as a set of tangible and intangible values that relate to people, companies and governments in a triple propeller. With the purpose of examining the application of the concept of Knowledge City, this article presents a unique case study with the object of study being the Mexican city of Monterrey, considered an emerging knowledge city. The case of Monterrey reveals opportunities marked by the knowledge society, since it requires the mobilization of endogenous resources, just as the examples observed in this article show us the fact that the resources of knowledge already exist and have a kind of "In cultural and historical values, developed in an organic and unique way. Regarding the limitations of the study, it is important to consider the time cut restricted to 2008 and 2009, which limited the analysis of the case in relation to the most recent events, such as the installation of drug cartels in the city that shaken their plans and strategies. These recent events represent a perspective for the continuation of the study of the case of Monterrey oriented to the analysis of the impacts of violence and organized crime in its capital system.

Keywords: Cities of knowledge. Monterrey. Case study.

\footnotetext{
${ }^{1}$ Aluna do mestrado em Administração da Universidade de Caxias do Sul (UCS). frizzon@yahoo.com.br

${ }^{2}$ Doutora em Ciências da Comunicação e da Informação pela Université de Poitiers, França. Professora do mestrado em Administração da Universidade de Caxias do Sul (UCS). afachinelli@gmail.com

${ }^{3}$ Aluna do doutorado e mestre em Administração pela Universidade de Caxias do Sul (UCS).

${ }^{4}$ Mestre em Design Estratégico pela Universidade do Rio dos Sinos (Unisinos). Professor da Universidade de Caxias do Sul (UCS). misael_ montana@yahoo.com.br

${ }^{5}$ Aluno do mestrado em Administração da Universidade de Caxias do Sul (UCS). edson.fontana@hotmail.com
} 
Ao longo da História é possível discernir grandes mudanças no perfil das cidades. No passado, as cidades da era pré-industrial constituíram-se como assentamentos compactos, alguns deles autossuficientes, incorporando funções agrícolas básicas e habilidades técnicas para sobreviver; outras, domínios das elites culturais e religiosas, foram desenvolvidas para atender às suas necessidades e outras, ainda, desenvolveram-se, primeiramente, como centros de comércio. Mais adiante no tempo vê-se uma ruptura no desenvolvimento das cidades com a chegada da Revolução Industrial. Muitas tornaramse centros de fabricação, tendo seu desenvolvimento determinado pela disponibilidade de habilidades técnicas, presença de empresários, disponibilidade de matérias-primas, fontes de energia e meios e elementos para a importação e exportação de produtos acabados (MUSTERD; OSTENDORF, 2003).

Novos tipos de cidades apareceram após a Segunda Guerra Mundial, dando origem a regiões urbanas. Nestas, setores de serviços tornaram-se dominantes e a conexão às redes internacionais tornou-se ainda mais importante do que na era industrial. Após a troca de bens e produtos, o intercâmbio de pessoas, capitais e informações emergiu. Muitos consideram a informação um fator dominante na era da globalização, na qual os bancos, companhias de seguros e todos os tipos de serviços utilizam informações como a nova base para a troca. Assim como a era industrial foi baseada em energia, a era atual baseia-se na informação (CASTELLS, 2000). Conhecimento, cultura e criatividade tornaram-se novas palavras-chave na compreensão das transformações urbanas. Agora acredita-se que o futuro das cidades será vinculado a estes conceitos (MUSTERD; OSTENDORF, 2003).

Na década de 90 o movimento de Gestão do Conhecimento tomou forma graças à confluência de três condutores econômicos principais: a) as restrições de modelos de negócios industriais para capitalizar tecnologias da informação e comunicação; b) a aceleração crescente da taxa de obsolescência das competências produtivas e c) a necessidade de identificar, medir, entender e capitalizar ativos intangíveis, ou seja, conhecimento, contribuindo para a geração de riquezas e desenvolvimento social (CARRILLO, 2003). O desenvolvimento baseado em conhecimento é a resposta das ciências econômicas e de gestão para o surgimento das cidades do conhecimento (CARRILLO, 2003).

Assim, sistemas baseados em valor e dimensões capitais são elementos-chave para uma definição de Cidade do Conhecimento (GARCIA; CHAVEZ, 2014). Uma Cidade do Conhecimento é uma cidade concebida para cultivar o conhecimento (EDVISSON, 2002; DVIR; PASHER, 2004), é uma cidade baseada em sua capacidade de criar riqueza, na sua capacidade de gerar e aproveitar seus recursos de conhecimento por meio de redes de conhecimento formadas por empresas, pessoas e governos (CHATZKEL, 2004). Segundo Carrillo (2004), uma Cidade do Conhecimento é uma cidade na qual a cidadania compromete-se em uma tentativa deliberada e sistemática de identificar e desenvolver o seu sistema de capitais, com uma abordagem equilibrada e sustentável.

Com o objetivo de caracterizar o desenvolvimento baseado em conhecimento no contexto das cidades, o presente estudo examina o caso da cidade de Monterrey, México, como Cidade do Conhecimento. Inicialmente procedeu-se à revisão de literatura sobre os temas "knowledge cit* (cidade(s) do conhecimento) e "Monterrey" para a construção do referencial teórico do estudo. Posteriormente realizou-se o estudo de caso propriamente dito por meio de análise documental e entrevistas com membros 
da equipe do Tecnológico de Monterrey. Em 2004 o governo do Estado reuniu toda a região para o projeto Monterrey - Ciudad Internacional de Conocimiento. O projeto desencadeou um diagnóstico sobre a demanda de capitais tangíveis e intangíveis de Monterrey, resultando no primeiro painel de capitais integrado para a cidade, publicado em 2008 (GARCIA; CHAVEZ, 2014). O método empregado para o diagnóstico da cidade de Monterrey passou a ser adotado para o prêmio Most Admired Knowledge City (Makci) no mundo (WORLD..., 2010). Trata-se de um caso emblemático que define as bases conceituais e técnicas de avaliação das cidades na perspectiva do desenvolvimento baseado em conhecimento.

A cidade de Monterrey estabeleceu para si a visão estratégica de tornar-se uma Cidade do Conhecimento até o ano de 2020. Em outras palavras, a intenção é aumentar a produção bruta econômica do Estado de Nuevo León, no qual se situa a cidade, em termos de valor total dos serviços prestados por meio de indústrias e atividades econômicas que criam uma economia do conhecimento, centrada na cidade de Monterrey.

\section{CIDADE DO CONHECIMENTO}

A crescente importância atribuída ao desenvolvimento baseado em conhecimento (CARRILLO, 2006; KOMNINOS, 2002) contribui para reforçar o tradicional papel das cidades como um centro, no qual existe uma maior densidade de recursos de conhecimento (KNIGHT, 1995). A novidade associada ao desenvolvimento urbano baseado em conhecimento é a análise socioeconômica dos componentes e estratégias de gestão do conhecimento possibilitadas pelo conceito e em direção a uma análise do sistema de valores urbanos baseado na criação, intercâmbio e aplicação do conhecimento (CARRILLO, 2006). Isto significa migrar de um objeto de estudo focado em ilhas em que os processos de desenvolvimento e inovação ocorrem de uma forma mais intensa em direção a uma análise sistêmica das estratégias urbanas e do sistema de valores sociais associados à gestão do conhecimento (CARRILLO, 2006).

É inevitável perceber que algumas cidades médias estão mais bem posicionadas do que outras para "vencerem" na Sociedade do Conhecimento, nomeadamente aquelas com uma rede forte de serviços baseados no conhecimento e/ou com uma base de conhecimento e uma cultura de inovação forte (HILDRETH, 2006). A estrutura de um modelo baseado no conhecimento é basicamente uma taxonomia do capital urbano que deliberadamente e sistematicamente mapeia todos os recursos da cidade e todo o conhecimento necessário para alavancar o desenvolvimento equilibrado e sustentável das comunidades urbanas contemporâneas. Essa taxonomia é baseada em uma avaliação do sistema de capitais urbanos da cidade (CARRILLO, 1997; CARRILLO, 2002) e visa a identificar e valorizar o capital individual e coletivo em níveis urbanos.

De acordo com Yigitcanlar e Lönnqvist (2013), no cenário global, conhecimento e informação são vistos como chaves para a prosperidade econômica. O conceito de economia abordado aqui refere-se às teorias econômicas de Joseph Schumpeter (1975), que nos expõe a importância do processo de inovação em prol da vantagem competitiva. As organizações, a partir dessa visão, promovem a chamada "destruição criativa" que possibilita um processo de constante inovação e cultura de mudança alterando resultados, bem como os conceitos de valor e de capital. 
Segundo os estudos sobre inovação, os agentes e contextos envolvidos são determinantes para o motor da economia moderna, pois estes conseguem utilizar o conhecimento e os avanços tecnológicos em benefício da sustentabilidade (TIDD; BESSANT; PAVITT, 2008). A economia de uma cidade do conhecimento cria produtos de valor agregado usando a pesquisa, a tecnologia e os recursos intelectuais. O papel do conhecimento na geração de riqueza tornou-se uma questão crítica para as cidades e, nesse sentido, as administrações urbanas precisam descobrir novas abordagens para aproveitar as oportunidades consideráveis de produção de conhecimento.

As cidades do conhecimento são estabelecidas com o objetivo de alcançar a sustentabilidade e a melhoria da qualidade de vida, fornecer os serviços necessários, enriquecer a variedade de vida cultural e o conhecimento e aumentar as competências e conhecimentos dos cidadãos e dos trabalhadores como meio de desenvolvimento intelectual humano (YIGITCANLAR; O'CONNOR; WESTERMAN, 2008). O conceito de Cidade do Conhecimento é amplo e refere-se a todos os aspectos da vida social, econômica e cultural de uma cidade. Sua conceituação pode ser a seguinte: Cidade do Conhecimento é aquela que visa ao desenvolvimento baseado em conhecimento, incentivando continuamente os processos de gestão do conhecimento. Isto pode ser alcançado por meio da contínua interação entre seus agentes de conhecimento e ao mesmo tempo entre eles e os agentes de conhecimento de outras cidades. Design apropriado, redes de tecnologia da informação e comunicação e infraestruturas apoiam essas interações (ERGAZAHIS; METAXIOTIS; PSARRAS, 2004). Cidades do Conhecimento são singularmente capazes de enfrentar o desafio de combater os problemas críticos do planeta e forjar novas oportunidades porque elas têm concentrações de capital humano, infraestrutura e outros recursos necessários, bem como os valores e a orientação empresarial para criar soluções (ERGAZAHIS; METAXIOTIS; PSARRAS, 2006).

O conceito de Cidades do Conhecimento surgiu na década de 60 com Machlup (1962), porém tal conceito ganhou força nos anos 90. Desde essa década ocorre o movimento de Gestão do Conhecimento nas Organizações em que o processo de gerenciamento do capital intelectual, composto pelos fatores humano, estrutural, ambiental e de relacionamento, começou a obter destaque como mola propulsora para alavancar a competitividade nas empresas e instituições que visam a priorizar investimentos em mecanismos de aprendizagem organizacional. Nesse sentido, surgem as redes de conhecimento que promovem o intercâmbio de ideias e fomentam um cenário de inovação, não somente em corporações, mas em outros ambientes, como as cidades e as comunidades (SERAFIM, 2011). A sociedade do conhecimento, como entendida no seu princípio, dentro de uma perspectiva econômica, é aquela em que os setores que utilizavam o conhecimento de forma intensiva eram os que mais contribuíam com o crescimento da economia (ROHRBACH, 2007). Méndez, Michelini e Romeiro (2006) propõem uma caracterização do conceito como uma abordagem do desenvolvimento capaz de gerar e aplicar diversas formas de conhecimento para melhorar a competitividade econômica, o bem-estar da população, a sustentabilidade ambiental, maior participação do cidadão nos assuntos públicos e uma governança eficaz.

Outro desdobramento desse conceito é focado em tecnologia e desenvolvido pela World Foundation for Smart Communities: as cidades e comunidades desenvolvem-se por meio da tecnologia e da comunicação. Conforme esses preceitos, uma comunida- 
de inteligente pratica um esforço consciente para usar a tecnologia da informação para transformar o trabalho e a vida dentro de seus limites territoriais de forma significativa, ao invés de uma forma incremental (CALIFÓRNIA INSTITUTE FOR SMART COMMUNITIES, 2001). Em ambos os casos torna-se evidente a constituição dessas cidades fortemente baseadas na tecnologia e a digitalização como aporte técnico, bem como a capacidade organizacional das informações desse território mediante um sistema inovativo.

A literatura específica do campo do desenvolvimento baseado em conhecimento afirma que os seguintes fatores são determinantes para o crescimento das Cidades do Conhecimento: comprometimento do governo local, estadual e federal com o desenvolvimento das cidades; presença de grandes corporações; presença de pequenas empresas e startups; universidades de qualidade; participação pública e qualidade de vida e de meio ambiente (CARRILLO, 2006; LANDRY, 2006; YIGITCANLAR; VELIBEYOGLU; BAUM, 2008a, b). Komninos $(2002,2008)$ amplia um desdobramento da terminologia de cidades para comunidades, clusters ou mesmo regiões. Segundo o pesquisador, tornam-se inteligentes os territórios que possuem alta capacidade de aprendizado e inovação, que possuem um "DNA" criativo em sua população, assim como as instituições e empresas que geram conhecimento com seus sistemas de comunicação e mecanismos de gestão do conhecimento.

Ainda no que se refere à ótica de Komninos (2002, 2008), as Cidades do Conhecimento operam na integração de dimensões da inteligência humana, coletiva e artificial. Sobre a imersão dessas dimensões propostas, Florida (2002) define a primeira dimensão centrada nas pessoas da cidade, indivíduos munidos de inteligência, inventividade e criatividade que habitam o território. A segunda dimensão proposta está relacionada à inteligência coletiva da população de um determinado território. Nesse sentido, a comunidade coopera intelectualmente na criação, inovação e invenção, promovendo trocas de conhecimento e de criatividade intelectual. A última dimensão está relacionada à inteligência artificial, referente ao ambiente físico, digital e institucional de uma cidade. Sendo assim, a expressão "cidade inteligente" diz respeito às atividades relacionadas ao conhecimento e aos grupos detentores deste. A organização, cooperação e gestão social tornam-se fatores determinantes para o sucesso e desenvolvimento territorial dessas comunidades.

Conforme observações de Serafim (2011), nas últimas três décadas registrou-se um crescente esforço global para formulação de políticas públicas, marcos regulatórios, iniciativas e planos que estimulem as parcerias público-privadas para potencializar o desenvolvimento econômico e social a partir do uso intensivo do conhecimento, da ciência e da tecnologia. Corroborando essa visão, Deiser (2010) observa a ascensão das organizações fundamentadas em conhecimento. O autor aponta que nesses últimos 25 anos, as bases das economias ocidentais tornaram-se cada vez mais alicerçadas no conhecimento. Sendo assim, o valor dos produtos e serviços cada vez mais reside em seu capital intelectual inerente e os trabalhadores do conhecimento aos poucos passam a formar a nova força de trabalho. A ascensão da classe criativa, na visão do economista social Richard Florida, está aos poucos modificando a essência das sociedades ocidentais. Essa ascensão do conhecimento como base para a criação de valor muda a maneira como as organizações lidam com esse ativo. O processo de gestão do conhecimento torna-se fator-chave de sucesso em mercados competitivos (FLORIDA, 2002). 


\section{MÉTODO}

Diante do objetivo de ilustrar o conceito de Cidade do Conhecimento, o presente artigo apresenta o estudo de caso da cidade de Monterrey, México, como Cidade do Conhecimento. Para tal, este estudo, de caráter qualitativo exploratório (HENNINK; HUTTER; BAILEY, 2011; REMLER; VAN RYZIN, 2011), aborda a revisão de artigos que trazem os conceitos de Cidade do Conhecimento. Inicialmente procedeu-se a uma pesquisa bibliográfica, pois essa opção permite o acesso a uma fonte de dados que não recebeu ainda um tratamento analítico com o objetivo de buscar novas interpretações (DENZIN; LINCOLN, 2011; HENNINK; HUTTER; BAILEY, 2011).

Para isso foi realizada uma busca nas bases de dados Science Direct e Scopus, acessando http://www.ucs.br nos links Biblioteca - Bases de Dados - Bases de Dados no Portal de Periódicos da Capes - Base - (nome de cada uma das bases consultadas). Não houve limitação de períodos e usou-se como descritores os termos "knowledge cit*" (cidade(s) do conhecimento) e "Monterrey". A partir dos conceitos encontrados nos artigos indexados nestas bases de dados e no site www.knowledgecities.com) foi desenvolvido o referencial teórico desta pesquisa, relacionando os conceitos de Cidade do Conhecimento com as informações encontradas sobre a cidade de Monterrey.

Dando continuidade, procedeu-se ao estudo de caso propriamente dito. $O$ estudo de caso, segundo Yin (2015), é utilizado em muitas situações, contribuindo para o entendimento de fenômenos individuais, grupais, organizacionais, sociais, políticos, etc. 0 estudo de caso torna-se para o pesquisador "uma investigação empírica que investiga fenômenos contemporâneos em profundidade, especialmente quando os limites entre fenômenos e contextos não são claramente evidentes" (YIN, 2015, p. 17). Segundo Yin (2005), o estudo de caso é uma investigação empírica, um método que abrange planejamento, técnicas de coleta de dados e análise das informações. A fim de cumprir os preceitos da técnica de estudo de caso procedeu-se à análise documental e, posteriormente, entrevistas em profundidade com três membros da equipe do Tecnológico do Monterrey que coordenaram o projeto Monterrey Cidade do Conhecimento.

Assim, procedeu-se à análise documental, entendida por Silva et al. (2009) como a pesquisa que permite a investigação de determinada problemática não em sua interação imediata, mas de forma indireta, por meio do estudo dos documentos que são produzidos pelo homem e por isso revelam o seu modo de ser, viver e compreender um fato social. A fim de atender ao objetivo de pesquisa, foram coletados dados documentais referentes à cidade de Monterrey e informações de sites da Internet como: www. worldcapitalinstitute.org, www.knowledgesystems.org, www.cidadedoconhecimento. org.br, www.redebrasileira.org, ideias.rioapps.com.br, www.americansforthehearts.org, www.lung.org, www.intelligentcommunity.org, do International Journal of Innovation Community Forum e www.smartcitiesportugal.net, acessados no período de 6 a 30 de setembro de 2016, caracterizando uma pesquisa com base em dados secundários. Após a coleta de documentos e entrevistas, procedeu-se a análises dos dados encontrados visando a sua relação com os conceitos relativos à Cidade do Conhecimento encontrados na literatura consultada. 


\section{UNIDADE DE ANÁLISE: A CIDADE DE MONTERREY}

Monterrey é a capital do Estado de Nuevo León, no nordeste mexicano, localizada a uma distância de três horas da fronteira com o Texas (EUA) e a cerca de 12 horas da capital, Cidade do México. Uma rede de sistemas rodoviários e ferroviários conecta Monterrey a quatro fronteiras no Texas e a todas as cidades e portos de grande porte mexicanos, tornando-a um epicentro comercial e de negócios. Sua localização, geograficamente isolada entre duas cadeias de montanhas, é uma parte fundamental de seus capitais, bem como a resiliência dos seus cidadãos e a relação de colaboração que tradicionalmente desenvolveram com seus vizinhos texanos. Monterrey foi fundada em 1596 por imigrantes espanhóis, tendo um desenvolvimento econômico lento, baseado na agricultura. Na segunda metade do século 19, contudo, Monterrey iniciou suas tendências de desenvolvimento, primeiro como um centro de comércio, evoluindo mais tarde para um polo industrial. Durante a Guerra Civil (1861-1865) o comércio na região da cidade aumentou significativamente, com base em operações comerciais intensas com os Estados Confederados do Sul (WORLD..., 2010).

Na década de 1890, com a primeira fábrica têxtil da emergente indústria de Monterrey operando há sete anos, instalou-se na cidade uma empresa cervejeira, oportunizando o surgimento de empresas adicionais para fornecer matérias-primas para a cervejaria. Isso trouxe a especialização da indústria (processamento de alimentos e bebidas é destaque), que hoje caracteriza Monterrey. A consolidação econômica da cidade começou a ter lugar por volta de 1900, quando os empresários locais estabeleceram ali a primeira siderúrgica da América Latina. A fábrica desenvolveu um conjunto de plantas metalmecânicas e lojas, fundições, aparelhos domésticos e outras operações relacionadas, criando, assim, uma significativa área industrial especializada e uma cultura metalúrgica na região. Mais tarde, em 1945, um novo empreendimento lançou sua produção de aço na cidade, inovando no processo de fundição de ferro para eliminar o uso de fornalhas para a produção de aço. Logo tornou-se um processo patenteado, licenciado para vários países, o que acabou por consolidar Monterrey como a capital do aço no México (WORLD..., 2010).

Durante o século 20 o processo de industrialização trouxe crescimento e desenvolvimento para a cidade, transmitindo também políticas sociais fundamentais, educação, habitação, assistência médica em clínicas das empresas que foram subprodutos da industrialização em expansão de Monterrey. Tal desenvolvimento empresarial, juntamente com a resiliência dos cidadãos, traduziu-se em indicadores de negócios favoráveis e riqueza regional. Hoje, o Estado de Nuevo León totaliza uma população de 4,3 milhões, dos quais a cidade de Monterrey concentra mais de 90\% (WORLD..., 2010).

A região metropolitana de Monterrey comporta 4\% da população do país e contribui com $8 \%$ do seu PIB. Abriga a maior empresa de desenvolvimento de software e um dos maiores sistemas de Ensino Superior privado da América Latina (Itesm) mantém sua sede na cidade. $52 \%$ do seu orçamento é investido em educação, com ênfase na participação do setor privado. Existem 231 escolas técnicas, duas universidades técnicas e mais de 30 instituições de Ensino Superior, sendo a cidade uma das líderes mundiais em universidades virtuais (WORLD, 2010). 
Monterrey adotou uma abordagem de desenvolvimento de clusters com foco em desenvolvimento de softwares, indústria aeronáutica, biomedicina, autopeças e mecatrônica. Estes clusters são caracterizados por impulsionar valores, tais como o zelo pelo meio ambiente, o potencial de exportações, comércio, desenvolvimento de talentos e contratação de mão de obra qualificada com salários superiores à média do mercado. Em Monterrey é estimulada a colaboração entre a academia, o setor público e o setor privado. O papel de cada agente neste círculo de colaboração é: setor privado - criação de riquezas; academia - preparar o capital humano e setor público - promover e realizar o desenvolvimento. Os esforços voltam-se para a criação de uma Cidade do Conhecimento, no planejamento e execução, em que todas as partes interessadas estão envolvidas. Sua visão está focada no Ensino Superior, com pesquisa para alcançar o conhecimento capaz de ser aplicado de forma inovadora. A aprendizagem e a inovação são as prioridades (WORLD..., 2010).

Monterrey, como uma cidade metropolitana, é moldada por suas condições geo-históricas únicas, desenvolvendo formas originais de capital humano coletivo, definido e caracterizado por sua condição de fronteira. Bolsões de pobreza são notórios em toda a região, apesar das iniciativas recentes do governo de Monterrey, que procurou convergir uma das economias locais mais prósperas do México com a economia petroleira da fronteira texana (GOBIERNO..., 2004). Ao contrário das fronteiras Juarez-El Paso ou Sonora-Arizona, lideranças de Monterrey têm procurado desenvolver relacionamentos fortes com seus vizinhos texanos por meio da cooperação orientada aos negócios e à academia. Isso foi possível devido aos principais pontos fortes educacionais da cidade e ao sistema de universidades, conforme identificado por Wolfe (2004).

Quanto à indústria, Monterrey destaca-se no setor de bebidas, vidro, processamento de alimentos, petroquímico, cimento, aço, eletrodomésticos, automotivo, eletrônico e telecomunicações. Outros grupos emergentes são software, biomedicina, aeronáutica e mecatrônica. Com efeito, Monterrey, como capital de Nuevo León, tornou-se uma comunidade urbana no século 20, com um proeminente potencial industrial, comercial e educacional no contexto mexicano (GARCIA; CHAVEZ, 2014). Monterrey tem sido considerada a capital industrial do México e em sua área metropolitana está San Pedro Garza Garcia, um dos municípios com maior índice de desenvolvimento humano para as Américas e o mundo (GARCIA; CHAVEZ, 2014).

Nos últimos anos Monterrey tem mantido uma posição de liderança em competitividade no México (INSTITUTO..., 2012; ORGANIZATION..., 2009). A competitividade de Monterrey baseia-se em sua capacidade de atrair, reter e desenvolver o talento humano e em investimentos para produzir bens e serviços de alto valor agregado para gerar emprego e qualidade de vida para seus habitantes (GARCIA; CHAVEZ, 2014).

A cidade de Monterrey estabeleceu para si a visão estratégica de tornar-se uma Cidade do Conhecimento até o ano de 2020. Em outras palavras, a intenção é aumentar a produção bruta econômica do Estado de Nuevo León em termos de valor total dos serviços prestados por meio de indústrias e atividades econômicas que criam uma economia do conhecimento, centrada na cidade de Monterrey. O site do governo do Estado define uma Cidade do Conhecimento como um território geográfico onde governo, empresas e sociedade elaboram um plano estratégico com o propósito comum de construir uma economia baseada no conhecimento (MONTERREY..., 2007). Assim, até 
o momento, Monterrey é classificada como uma Cidade do Conhecimento emergente, juntamente com Beijing, Brisbane, Dubai, Istambul, Kuala Lumpur e Shenzhen (HUGGINS; STRAKOVA, 2012; YIGITCANLAR; SARIMIN, 2011; YIGITCANLAR; VELIBEYOGLU, 2008; ZHAO, 2010).

\section{BALANÇO DO SISTEMA DE CAPITAIS DE MONTERREY}

O Centro de Sistemas del Conocimiento, uma instituição dedicada a promover o uso consciente do conhecimento como um fator de desenvolvimento pessoal e coletivo, contribuindo também para o crescimento sustentável das comunidades, apresenta 0 diagnóstico de Monterrey como Cidade do Conhecimento pela perspectiva do Sistema de Capitais, que consiste em um documento integral dos elementos de valor, tanto tangíveis quanto intangíveis da comunidade. Este diagnóstico pretende mostrar o potencial de desenvolvimento baseado em conhecimento de uma comunidade urbana por intermédio do balanço de suas contas de capital. O perfil de capitais urbanos converge com propostas desenvolvidas pela Price Waterhouse Coopers (2007) sobre as 40 Cidades do Futuro, a partir de sua base de capital de conhecimento e do World Capital Institute para eleger as Cidades de Conhecimento mais admiradas do mundo. Ambos usam o mesmo enfoque de sistema de capitais aplicado a esse relatório desenvolvido pelo Tecnológico de Monterrey (2008) e fonte de dados para o presente estudo.

O perfil de Monterrey como Cidade do Conhecimento foi realizado a partir da perspectiva do Sistema de Capitais que articula dados e informações sobre todos os elementos de valor, tangíveis e intangíveis de uma comunidade, e busca determinar o potencial de desenvolvimento baseado em conhecimento de uma comunidade urbana por meio do registro de ativos e passivos em contas de capitais. São oito categorias maiores que se desagregam até a obtenção de um mapa de valores únicos e singulares de uma cidade. No caso de Monterrey foram realizados três exercícios: um perfil qualitativo e descritivo consistente e uma compilação de dados quantitativos individuais e isolados; um perfil quantitativo e comparativo em âmbito nacional, latino-americano e mundial para cada variável; um balanço dos capitais com os passivos e ativos que se destacaram em todas as categorias e que integram os perfis quantitativo e qualitativo. As contas de capital configuram o mapa de valor e se articulam em sete categorias de capital: Identidade, Inteligência Relacional, Financeiro, Humano Individual, Humano Coletivo, Instrumental Tangível e Instrumental Intangível (TECNOLÓGICO..., 2008). A análise das contas de capital da cidade de Monterrey a configura como uma Cidade do Conhecimento emergente conforme detalhado a seguir.

Quanto ao Capital de Identidade, o valor positivo de sua personalidade regional e urbana, assim como uma recente renovação em áreas proeminentes da fisionomia urbana e da planta técnico-industrial apontam para uma identidade regiomontana que se consolidará e evoluirá, porém Monterrey ainda não está inclusa nas grandes ligas das metrópoles globais. A ausência de uma gestão de marca, manutenção e pertencimento somada ao posicionamento global restrito de seu nome, assim como a recente deterioração de sua imagem de segurança, comprometem sua viabilidade como Cidade do Conhecimento. Por outro lado, o sentido de recuperação e renovação da sociedade regiomontana são um forte ativo, o qual, canalizado por políticas baseadas em conhecimento, poderá estimular um salto qualitativo em seu desenvolvimento. 
O Capital de Inteligência é um capital novo, estratégico e distintivo para as cidades do conhecimento. Há uma clara área de oportunidade para crescimento, uma área em que se pode obter bons resultados a curto prazo, à diferença de outros capitais. Monterrey está posicionada na vanguarda com a Lei de Desenvolvimento Baseado em Conhecimento, o Programa Monterrey Ciudad Internacional de Conocimiento e o Parque de Pesquisa e Inovação Tecnológica. Tem a opção de complementar estas iniciativas com um Centro de Futuro e um Sistema de Inteligência Estratégica a partir de suas contas de conhecimento no sistema de capitais. As contas públicas são um instrumento-chave para que a comunidade assuma sua responsabilidade e participação no processo de consolidar Monterrey como uma Cidade do Conhecimento.

Quanto ao Capital Financeiro, Monterrey tem sido um baluarte em produtividade, competitividade e liderança industrial no México. Depois de uma década de relativa estagnação, encontra-se agora em um processo de evolução de sua planta industrial, setores estratégicos, base tecnológica, perfil produtivo, mercado de trabalho, surgimento de empresários, estruturas corporativas, estilos de investimento e competências empreendedoras. Por outro lado, a turbulência econômica mundial apresenta ameaças quanto ao custo de matérias-primas, energia e alimentos, assim como pressões competitivas globais, agravando diferenças históricas locais em distribuição de renda. Sociedade civil, setores produtivos, governo e universidades precisam estar conscientes do momento e serem capazes de alcançar os níveis de organização necessários para superar essas ameaças no contexto de uma economia de conhecimento.

Já o Capital Relacional da cidade de Monterrey mostra elementos favoráveis e potenciais em termos de vínculo externo, propiciando seu eventual posicionamento como um importante nó (inter)continental devido a sua localização geográfica. Apresenta, também, um saldo negativo em termos de coesão social interna, devido ao recente aumento da insegurança, da ampliação da faixa de pobreza na última década e, sobretudo, a marginalização da mulher e a prevalência da violência doméstica em quase todos os níveis sociais. Esta circunstância propicia um círculo vicioso de marginalização-pobreza-criminalidade-corrupção que começa a debilitar a coesão social interna, o qual é estendido ao país como um todo, sem o mérito de respostas locais planejadas e eficazes.

O Capital Humano Individual da cidade de Monterrey apresenta grandes contrastes em termos de educação, nutrição, autocuidado e participação na vida produtiva. Os comparativos nacionais e regionais de desempenho escolar são destacados e recebem crescente atenção, porém o desempenho em âmbito mundial é pobre. Por outro lado, os maus hábitos de ingesta de bebidas e alimentos, de autocuidado, assim como a pouca leitura, diminuem o valor agregado que cada cidadão pode oferecer à comunidade, gerando um enorme e evitável custo social de saúde e a deterioração da qualidade de vida. Consolidar os avanços educacionais, levá-los a padrões internacionais e esperar que se manifestem na comunidade as ordens formativas básicas, incluindo hábitos alimentares e inteligência emocional, são pré-requisitos para uma cidade de conhecimento em desenvolvimento.

A competitividade urbana e a qualidade de vida têm sido a base do progresso de Monterrey e um ponto de referência nacional e latino-americano. Este é um ativo que merece ser assegurado e desenvolvido. O perfil demográfico apresenta um inevitável envelhecimento da população, diminuição da força de trabalho e incremento do custo 
social, o que requer o desenvolvimento acelerado das capacidades coletivas. É imperativo atacar as ameaças que podem ter consequências preocupantes e deixar graves sequelas para a segurança e a qualidade de vida, deste modo contribuindo e fortalecendo o Capital Humano Coletivo de Monterrey.

Quanto ao Capital Instrumental Tangível, Monterrey, por ser uma cidade de montanhas, fronteira do nordeste mexicano, tem tanto em sua localização geográfica como em sua infraestrutura industrial um acervo de capital tangível proeminente, que foi incrementado por uma infraestrutura de serviços em anos recentes. Aguardam por solução problemas em matéria de conectividade e informatização do transporte urbano e mobilidade, assim como congestionamentos importantes e problemas severos quanto ao cuidado com o meio ambiente e recursos renováveis que poderiam comprometer sua viabilidade futura.

Sobre o Capital Instrumental Intangível pode-se afirmar que Monterrey está estabelecida sobre notáveis capacidades coletivas de cultura, empresas e Educação Superior. Um impulso sem precedentes das capacidades de pesquisa científica e inovação, assim como de vida cultural, põem a capital de Nuevo León em uma posição de liderança regional, porém as capacidades coletivas que sustentam a organização social, as instituições e a vida comunitária encontram-se hoje diminuídas pelo crescimento do crime organizado e da corrupção. Para que os novos esforços de desenvolvimento científico, tecnológico, industrial e cultural amadureçam em sistemas que alimentem a comunidade e renovem a produtividade, o emprego, a vida e a cultura regiomontanos, são pré-requisitos a erradicação da corrupção, a prática da transparência governamental como hábito e a vigência do Estado de Direito em todas as suas ordens.

O relatório do Tecnológico de Monterrey (2008) destaca alguns pontos em cada uma das sete contas de capital que necessitam de investimentos para que a cidade atinja o objetivo de tornar-se uma Cidade do Conhecimento até o ano de 2020. Assim, quanto ao Capital Identidade, os aspectos mais proeminentes são:

- Genealogia e atratividade: a cidade de Monterrey herdou um distinto perfil do qual se nutre o sentido de identidade e pertencimento de seus habitantes. Este manifesta-se em sua atratividade regional como centro industrial e de negócios. Sua meta é salvaguardar este perfil e desenvolver sua atratividade.

- Marca da cidade: sua gestão é uma área de oportunidade, posto que não há um registro oficial de marca nem uma iniciativa formal de administração da identidade da cidade. Isto se aplica, também, ao reconhecimento do nome, diferenciação e posicionamento internacional.

- Imagem: a imagem da cidade se vê afetada pela onda de violência, crime organizado e corrupção, que não são exclusivos de Nuevo León, mas que estão corroendo sua qualidade de vida e atratividade.

Na conta de Capital de Inteligência os aspectos mais proeminentes são:

- Marca Institucional: Nuevo León é o primeiro Estado do país a promulgar uma lei para o fomento do Desenvolvimento Baseado em Conhecimento e institucionalizar um Programa de Cidade de Conhecimento. A cidade conta com um inventário generoso de capacidades públicas e privadas de inteligência. 
- Sistema de Inteligência Estratégica: faz falta integrar funcionalmente as capacidades públicas e privadas existentes para construir o Sistema de Inteligência Estratégica da cidade.

- Centro de Futuro: mesmo que Monterrey conte com vários centros de prospecção tecnológica e alguns de planejamento estratégico, não conta com um Centro de Futuro, que por meio do sistema de capitais pode realizar prospecções fundamentadas nas capacidades e opções de desenvolvimento do capital de conhecimento da cidade.

Na conta de Capital Financeiro os principais aspectos são:

- Produtividade: Monterrey está posicionada como polo industrial e destaca-se na produção de concreto e cimento. Contribui com 7,6\% do PIB mexicano, apesar de seu crescimento ter desacelerado. Sua meta é evoluir para uma produção baseada em conhecimento.

- Investimentos: ocorre a inversão do capital local em estrangeiro, com o crescimento da globalização, mas com a consequência de deixar de criar empregos e decrescimento econômico em âmbito local.

- Distribuição de Investimentos: desde 1980 iniciou-se a distribuição de investimentos diante do abismo social que estava se formando. Assim, houve um aumento na oferta de postos de trabalho e melhoria nas condições de trabalho, porém isso favoreceu somente os com melhor formação educacional, enquanto o investimento real nos extratos mais baixos da população diminuiu.

Quanto ao Capital Relacional, os aspectos mais proeminentes são:

- Vinculação Internacional: conta com condições relacionais geoestratégicas, representacionais, econômicas, comerciais, industriais e logísticas que se convertem em um potencial de nó (inter)continental, se souber capitalizá-los.

- Participação Cidadã: existe uma área de oportunidade, envolvimento e participação tanto em organizações civis e políticas como de voluntariado e ONGs. Mesmo tendo alcançado avanços nesse sentido, a limitada participação feminina e a cultura cívica têm detido o avanço do envolvimento cidadão.

- Segurança pública e equidade de gênero: o aumento da criminalidade têm transformado a vida na cidade, que até pouco tempo atrás era uma das cidades mais seguras do país.

No que se refere ao Capital Humano Individual destacam-se os seguintes aspectos:

- Desempenho escolar em âmbito nacional e latino-americano: o desempenho escolar dos estudantes está entre os níveis mais elevados. No teste latino-americano Serce, que inclui o Estado de Nuevo León em comparação com o país, o Estado ocupou o segundo lugar geral.

- Desempenho escolar referenciado mundialmente: os testes Enlace e Pisa evidenciaram os problemas que estão na raiz do setor educacional, tanto em plano nacional como regional, que afetam diretamente o desenvolvimento do capital humano. 
- Obesidade e hábitos de autocuidado: os maus hábitos de consumo, ingesta e autocuidado estão mostrando suas consequências; obesidade, diabetes e outras enfermidades tão letais quanto evitáveis, vêm registrando aumento na população infantil.

Já quando se descreve o Capital Humano Coletivo os aspectos mais proeminentes são:

- Qualidade de vida e competitividade urbana: as estatísticas mostram um índice de desenvolvimento humano, alfabetização e esperança de vida ao nascer acima da média nacional, assim como um ambiente propício para a indústria, os serviços e os investimentos, porém falta atingir índices semelhantes em âmbito mundial.

- Perfil demográfico: a curva da população economicamente ativa não se encontra em um momento favorável. Urge elevar o nível de preparação geral para a vida e o trabalho.

- Tabagismo e alcoolismo: encontram-se acima da média nacional em alguns indicadores de bem-estar e saúde pública. Os níveis de consumo de tabaco e álcool e a crescente drogadição demandam por políticas urgentes de atenção.

A conta de Capital Instrumental Tangível apresenta como aspectos mais proeminentes:

- Localização e patrimônio natural: sua paisagem é privilegiada. Tem acesso a centros de produção e consumo chaves na América do Norte e, por sua vez, acessibilidade a mercados nacionais e internacionais.

- Conectividade e informatização: a infraestrutura social digital - acesso a conexões de banda larga, provedores de Internet, uso de computadores em escolas e lugares e analfabetismo digital estão acima dos índices relacionados a outras Cidades do Conhecimento emergentes.

- Sustentabilidade ambiental: deve estabelecer uma normatização adequada para seu desenvolvimento sustentável. Isto se refere ao manejo do meio ambiente, à qualidade do ar, ao volume de tratamento de esgotos e às políticas de transporte e mobilidade urbana.

O Capital Instrumental Intangível é caracterizado pelos seguintes fatores:

- Desenvolvimento da oferta cultural: tanto as belas artes como as expressões populares, usos e costumes, artesanato e tradições e o rico patrimônio cultural merecem ser mais bem capitalizados.

- Pesquisa e inovação: é necessário desenvolver o sistema regional de inovação integrando, organicamente, tanto a produtividade e a competitividade quanto a vida urbana e a inovação social.

- Governabilidade: os sinais de falta de coesão social manifestam-se localmente na corrupção e no crime organizado. Assim, é necessário desenvolver ações de erradicação da violência, da corrupção e da ilegalidade que minam a evolução social. 


\section{ANÁLISE E DISCUSSÃO DOS RESULTADOS}

Os territórios e regiões estão passando por uma transformação fundamental de uma entidade geográfica, política e cultural para uma tríplice hélice entre empresas, universidades e agências governamentais que gerenciam novas iniciativas para a inovação regional. Segundo os pesquisadores Koepp (2002) e Etzkowitz (2009), as condições para o crescimento econômico de alta tecnologia não são fenômenos espontâneos. Segundo esses, o processo de mudança não é exclusivamente motivado pelo mercado ou pelas políticas. Na fase inicial, o desenvolvimento baseado na ciência surge da atuação conjunta das universidades e instituições de pesquisa. Nesse sentido, regiões como o Vale do Silício, Boston e Linköping, na Suécia, tornam-se exemplos de formação e desenvolvimento de empresas. Esses ditos clusters assumem uma identidade de formação contínua de empresas, um processo de renovação muito além da tecnologia específica que era sua grande fonte de energia. Surge, nesse paradigma, um "ecossistema" sustentado pela inovação e formação de instituições, capaz de gerar novas tecnologias e conceitos de negócio à medida que eles surgem e, de igualmente, atraí-los para a região em que estão situados.

À medida que estas regiões formulam estratégias de inovação baseadas no conhecimento, os atores e agentes se transformam. Com o desenvolvimento das atividades empresariais, um cluster muitas vezes ganha vida própria, não dependendo mais diretamente de uma universidade ou iniciativa regional. As identidades regionais são transformadas à medida que fatores tradicionais de produção, como a terra, mão de obra e capital dão lugar ao conhecimento, tanto em indústrias de alta tecnologia quanto naquelas mais rudimentares.

Sendo o conhecimento, a cultura e a criatividade os "motores" para o desenvolvimento urbano e social das cidades, conforme Musterd e Ostendorf (2003), nos dias de hoje despontam as Cidades do Conhecimento e, entre elas, está Monterrey. A globalização trouxe a quebra de paradigmas de produção já consolidados, o surgimento das tecnologias da informação e comunicação, a obsolescência acelerada das competências produtivas e a necessidade de buscar novos valores para a geração de riquezas e desenvolvimento. O modelo de Cidades do Conhecimento emerge como alternativa de enfrentamento a esse novo paradigma.

O sistema de valores engloba os elementos-chave para a formação de uma Cidade do Conhecimento (GARCIA; CHAVEZ, 2014), concebidos para cultivar, promover e disseminar o conhecimento. $O$ balanço do sistema de capitais de Monterrey mostra, em seu âmbito de Capital de Identidade, que ela precisa posicionar-se como uma cidade não mais destaque industrial, mas Cidade do Conhecimento, consolidando sua intenção de evoluir nesse conceito e fortalecer essa imagem de cidade inovadora, tecnológica e que enfatiza o investimento em educação ( $52 \%$ de sua receita é destinada ao desenvolvimento educacional). O sentimento de pertencimento precisa ser estimulado junto aos cidadãos a fim de promover o envolvimento nas iniciativas de Cidade do Conhecimento, juntamente com o combate à crescente violência que está trazendo um sentimento de insegurança à comunidade. 
Monterrey está posicionada na vanguarda com a criação da Lei de Desenvolvimento Baseado em Conhecimento, o Programa Monterrey Cidade Internacional do Conhecimento e o Parque de Pesquisa e Inovação Tecnológica. Essas iniciativas sinalizam o interesse do poder público em estimular e auxiliar no desenvolvimento de iniciativas de fortalecimento do Capital de Inteligência de Monterrey.

No que se refere ao Capital Financeiro, Monterrey está passando por um período de mudanças em virtude da turbulência econômica mundial, desigualdades sociais e necessidade de enfrentamento de ameaças ao seu desenvolvimento econômico como um todo. A sociedade, em conjunto com o poder público, empresas e universidades, precisa engajar-se na busca de alternativas que fortaleçam iniciativas em sua economia do conhecimento em construção.

O Capital Relacional de Monterrey agrega vantagens para seu sistema de capitais devido à localização geográfica da cidade, porém as desigualdades sociais, o aumento da insegurança, a marginalização da mulher e a violência doméstica necessitam de medidas corretivas a fim de fortalecer esse capital com ações planejadas, eficazes e contínuas. Uma cidade não pode ser considerada "Cidade do Conhecimento" quando não desenvolve ações para conter a violência, estimular o desenvolvimento cidadão e fortalecer o papel feminino na sociedade.

Monterrey enfrenta algumas demandas também quanto ao Capital Humano Individual. Apesar de destacar-se nos indicadores de educação em âmbitos nacional e latino-americano, há a necessidade de fortalecer esses indicadores no plano mundial e desenvolver ações em saúde pública para o enfrentamento das doenças relacionadas aos maus hábitos de consumo e alimentação, tabagismo, alcoolismo, drogadição, de autocuidado, doenças letais e evitáveis que oneram o sistema de saúde, mas que podem ser tratadas com medidas preventivas, proporcionando uma melhor qualidade de vida à população, menor gasto público e um desenvolvimento humano consistente a uma Cidade do Conhecimento.

A competitividade urbana e a qualidade de vida têm sido a base do progresso de Monterrey, tornando-a referência nacional e latino-americana. Para fortalecer o Capital Humano Coletivo de Monterrey são necessárias ações para o enfrentamento do enveIhecimento da população, fortalecimento da força de trabalho e manutenção da qualidade de vida das pessoas.

Monterrey necessita de soluções em matéria de conectividade, informatização do transporte urbano e mobilidade, além de iniciativas de fortalecimento de sua rede de Tecnologia da Informação e Comunicação, integrando o cidadão nessa rede. Ações visando à preservação do meio ambiente e dos seus recursos naturais também são importantes para consolidar seu Capital Instrumental Tangível.

Quanto ao Capital Instrumental Intangível, Monterrey destaca-se em sua cultura, perfil empreendedor e educação. As iniciativas em pesquisa e inovação e sua vida cultural colocam a cidade em uma posição de liderança em âmbito regional. $O$ enfrentamento da violência, do crime organizado e da corrupção proporcionarão um clima de confiança, melhor qualidade de vida e segurança à população, fortalecendo as iniciativas de desenvolvimento tecnológico, cultural, educacional e social da comunidade. 


\section{CONSIDERAÇÕES FINAIS}

Diante do objetivo deste artigo, de ilustrar o conceito de Cidade do Conhecimento a partir de um estudo de caso, pode-se considerar que o objetivo foi alcançado. $\mathrm{O}$ case da cidade mexicana de Monterrey mostrou-se riquíssimo, pois fornece um panorama completo do Sistema de Capitais da cidade, que está desenvolvendo políticas dentro das iniciativas de Desenvolvimento Baseado em Conhecimento e, assim, está se encaminhando para tornar-se uma legítima Cidade do Conhecimento.

A revisão da literatura revelou que a evolução do conceito de Cidades do Conhecimento é cada vez mais convergente quanto à aplicação do termo, no entanto as entrevistas realizadas com a equipe de Monterrey e a observação direta indicam que a principal dificuldade situa-se na aplicação do atributo definidor: "de conhecimento" ou "baseada em conhecimento". Uma perspectiva mais extensiva associa os atributos definidores às capacidades técnico-científicas e educativas como potencializadoras do crescimento econômico, enquanto uma perspectiva mais vanguardista associa o atributo diferenciador à gestão equilibrada do capital intelectual. Nesse sentido, o atributo "do conhecimento" refere-se a todas as dimensões da experiência humana, em que o valor não é expresso apenas física e monetariamente, mas encontra sua expressão também nas dimensões humanas, sociais, culturais e, em geral, em todos os âmbitos da realidade urbana. Assim, o desenvolvimento baseado em conhecimento considera especialmente os ativos intangíveis para resgatá-los e incorporá-los ao mapa estratégico de uma cidade (TECNOLÓGICO..., 2008).

Monterrey precisa ainda enfrentar muitos desafios para o alinhamento de suas contas de capital, porém muito já foi feito e isso se reflete nos principais indicadores. A cidade é líder em educação no país, na qualidade de vida e agraciada por recursos naturais singulares. Além disso, está localizada em uma região de fronteira, o que favorece seu desenvolvimento econômico e acessibilidade, fatores que também já mostraram seu valor ao longo da história de desenvolvimento da cidade.

As Cidades do Conhecimento do século 21 possuem a forte presença da universidade na configuração do cenário atual. A expertise acadêmica, marcada pela significativa presença dos knowledge workers em conjunto com unidades de pesquisa, inovação e desenvolvimento, potencializam o sucesso da sociedade do conhecimento e tem contribuído para a estruturação econômica e social de Monterrey e outros modelos de Cidades do Conhecimento. De acordo com a experiência de Monterrey, no entanto, para que esse desenvolvimento aconteça, faz-se necessário a quebra de barreiras formais que causam lentidão e burocracia em algumas ocasiões e a constante ampliação das redes de cooperação e parcerias em diferentes escalas.

De acordo com o balanço de capitais da cidade de Monterrey, foi possível observar que esta busca se estruturar como uma Cidade do Conhecimento, tendo atingido indicadores importantes, tais como o comprometimento do governo local com o desenvolvimento da cidade, a presença de grandes corporações e de pequenas empresas e startups, universidades de qualidade, participação pública, qualidade de vida e meio ambiente. 
O caso de Monterrey revela oportunidades balizadas pela sociedade do conhecimento, uma vez que essa requer a mobilização de recursos endógenos, assim como os exemplos observados nesse artigo nos apresentam o fato de que os recursos do conhecimento já existem e possuem uma espécie de "enraizamento" em valores culturais e históricos, desenvolvidos de forma orgânica e única.

Quanto às limitações do estudo, é importante considerar que o recorte temporal baseou-se no período em que foi realizado o diagnóstico da cidade de Monterrey, nos anos 2008 e 2009. Os fatos e fenômenos analisados estão circunscritos a esse tempo, o que limitou a análise do caso em relação a fatos mais recentes que tornaram a cidade conhecida no mundo, tais como a instalação de cartéis de narcotráfico que abalaram seus planos e estratégias. Por outro lado, esses fatos recentes representam uma perspectiva para a continuação do estudo do caso de Monterrey orientado para a análise dos impactos da violência e da criminalidade organizada no seu sistema de capitais. Apesar dos fatos recentes, Monterrey, Cidade do Conhecimento, continua sendo um caso referencial para cidades ao redor do mundo, pois demonstrou que é possível organizar a estrutura de valores de uma cidade de forma que ela possa buscar alternativas de desenvolvimento em bases vinculadas à sua identidade e singularidade.

\section{REFERÊNCIAS}

CALIFORNIA INSTITUTE FOR SMART COMMUNITIES. 2001. Disponível em: http://www.smartcommunities.org. Acesso em: 9 set. 2016.

CARRILLO, F. J. Managing knowledge-based value systems. Journal of Knowledge Management, v. 1, n. 4, p. 280-286, 1997.

CARRILLO, F. J. Capital systems: Implications for a global knowledge agenda. Journal of Knowledge Management, v. 6, n. 4, p. 379-399, 2002.

CARRILLO, F. J. A note on Knowledge-based Development. Technical Note CSC2003-07.Monterrey: Centro de Sistemas de Conocimiento, Tecnológico de Monterrey y The World Capital Institute, 2003.

CARRILLO, F. J. Capital cities: A taxonomy of capital accounts for knowledge cities. Journal of Knowledge Management, v. 8, n. 5, p. 28-46, 2004.

CARRILLO, F. J. CARRILLO, F. J. (ed.). Knowledge Cities. Approaches, Experiences and Perspectives. Oxford: Elsevier, 2006.

CASTELLS, M. European cities, the informational society, and the global economy. In: DEBEN, L.; HEINEMEIJER, W.; VAART, D. Van Der (ed.). Understanding Amsterdam. Essays on Economic Vitality, City Life and Urban Form. Amsterdam: Het Spinhuis, 2000. p. 1-18.

CKS. Center For Knowledge System. Disponível em: http://www.knowledgesystems.org. Acesso em: 9 set. 2016.

CHATZKEL, J. Greater Phoenix as a knowledge capital. Journal of Knowledge Management, v. 8, n. 5, p. 28-46, 2004.

DEISER, R. Organizações inteligentes: como a arquitetura da aprendizagem sustenta a estratégia corporativa. São Paulo: SSJ, 2010.

DENZIN, N. K.; LINCOLN, Y. S. (Ed.). The Sage handbook of qualitative research. Sage, 2011.

DVIR, R.; PASHER, E. Innovation engines for knowledge cities: An innovation ecology perspective. Journal of Knowledge Management, v. 8, n. 5, p. 16-27, 2004.

EDVISSON, L. Corporate longitude. Harlow: Pearson Education, 2002.

ERGAZAHIS, K.; METAXIOTIS, K.; PSARRAS, J. Towards knowledge cities: conceptual analysis and success stories. Journal of Knowledge Management, v. 8, n. 5, p. 5-15, 2004.

ERGAZAHIS, K.; METAXIOTIS, K.; PSARRAS, J. Knowledge cities: the answer to the needs of knowledge-based development. Vine, v. 36, n. 1, p. 67-84, 2006.

ETZKOWITZ, H. Hélice tríplice: universidade-indústria-governo: inovação em ação. Porto Alegre: EDIPUCRS, 2009. 
FLORIDA, R. The Rise of the Creative Class and how it's Transforming Work, Leisure, Community and Everyday Life. New York: Basic Books, 2002.

GARCIA, B. C.; CHAVEZ, D. Network-based innovation systems: a capital base for the Monterrey city-region, Mexico. Expert Systems with Applications, v. 41, p. 5.636-5.646, 2014.

GOBIERNO DE NUEVO LEÓN. Programa estratégico de ciencia, tecnología e innovación, 2004. Disponível em: http://www.nl.gob.mx. Acesso em: 19 set. 2016.

HENNINK, M.; HUTTER, I.; BAILEY, A. Qualitative research methods. Thousand Oaks: Sage Publications, 2011.

HILDRETH, Paul Adrian. Roles and Economic Potential of English Medium-Sized Cities: a discussion paper. 2006. Disponível em: <www.surf.salford.ac.uk>. Acesso em: 18 set. 2016.

HUGGINS, R.; STRAKOVA, L. Knowledge-based economic development in emerging regions: Policy issues and implications in the Balkan peninsula. Regional Studies, v. 46, n. 7, p. 961-975, 2012.

INTELLIGENT COMMUNITY FORUM. Disponível em: http://www.intelligentcommunity.org. Acesso em: 18 set. 2016.

INTERNATIONAL JOURNAL OF INNOVATION COMMUNITY FORUM. Disponível em: http://www.inderscience.com/info/inarticletoc. .php?jcode=ijird\&year=2009\&vol=1\&issue=4. Acesso em: 20 set. 2016.

INSTITUTO MEXICANO PARA LA COMPETITIVIDAD. Índice de Competitividad Urbana 2012. El municipio: una institución diseñada para el fracaso. Propuestas para la gestión profesional de las ciudades. México D.F.: Imco, 2012.

KOEPP, R. Clusters of Creativity: enduring lessons on innovation and enterpreneurship from Silicon Valley and Europe's Silicon Fen. New York: John Wiley, 2002.

KOMNINOS, N. Intelligent Cities: Innovation, knowledge systems and digital spaces. London and Digital Spaces. London; Nova York: Routledge, 2002.

KOMNINOS, N. Intelligent Cities and Globalization of Innovation Networks. London; Nova York: Routledge, 2008.

KNIGHT, R. Knowledge-Based Development: Policy and Planning Implications for Cities Urban Studies, v. 32, n. 2, p. 225-260, 1995.

LANDRY, C. The Art of City Making. London: Earthscan, 2006.

LUNG. Disponível em: http://lung.com.br. Acesso em: 18 set. 2016.

MACHLUP, F. The Production and Distribution of Knowledge in the United States. 3. ed. Princeton, NJ: Princeton University Press, 1962.

MÉNDEZ, R.; MICHELINI, J.; ROMEIRO, P. Redes socio-instucionales e innovación para el desarrollo de las ciudades intermedias. Ciudad y Territorio Estudios Territoriales, v. 38, n. 148, p. 377-395, 2006.

MONTERREY CIUDAD INTERNACIONAL DE CONOCIMIENTO. Disponível em: http://www.nl.gob.mx/?P1/4intro_cd_conocimiento. Acesso em: 7 jul. 2007.

MUSTERD, S.; OSTENDORF, W. Creative Cultural Knowledge Cities: Perspectives and Planning Strategies. Built Environment, v. 30, n. 3, 2003.

ORGANIZATION FOR ECONOMIC CO-OPERATION AND DEVELOPMENT. Review of Innovation Policy. MexiCO; Paris: OECD, 2009.

PORTAL CIDADES DO CONHECIMENTO. Disponível em: http://www.cidadedoconhecimento.org.br. Acesso em: 20 set. 2016.

REDE BRASILEIRA DE CIDADES INTELIGENTES E HUMANAS. Disponível em: http://facebook.com.RBCleH/. Acesso em: 21 set. 2016.

REMLER, D. K.; VAN RYZIN, G. G. Research Methods in Practice: Strategies for Description and Causation. 2. ed. Sage Publishing, 2011.

ROHRBACH, D. The development of knowledge societies in 19 OECD countries between 1970 and 2002. Social Science Information, v. 46, n. 4, p. 655-689, 2007.

SERAFIM, L. O poder da inovação: como alavancar a inovação em sua empresa. São Paulo: Saraiva, 2011. SCHUMPETER, J. Capitalism, Socialism and Democracy. Nova York: Harper, 1975.

SILVA, L. R. C. da et al. Pesquisa documental: alternativa investigativa na formação docente. In: CONGRESSO NACIONAL DE EDUCAÇÃO, Curitiba, 2009. p. 4.554-4.566.

SMART CITIES PORTUGAL. Disponível em: http://smartcitiesportugal.net. Acesso em: 20 set. 2016.

TIDD, J.; BESSANT, J.; PAVITT, K. Gestão da inovação. Porto Alegre: Bookman, 2008.

TECNOLÓGICO DE MONTERREY. Página Inicial, 2008. Disponível em: https://tec.mx/es. Acesso em: 21 set. 2016. 
WOLFE, D. A. The role of higher education in regional innovation and cluster development. In: JONES, G.; MCCARNEY, P.; SKOLNICK, M. (ed.). Creating Knowledge, Strengthening Nations: The Changing Role of Higher Education. Toronto: University of Toronto Press, 2004. p. 167-194

WORLD CAPITAL INSTITUTE. 2010. Disponível em: http://www.worldcapitalinstitute.org/makci/makciawards-most-admired-knowledge-city. Acesso em: 29 set. 2016.

YIGITCANLAR, T.; LÖNNQVIST, A. Benchmarking knowledge-based urban development performance. Results from the international comparison of Helsinki. Cities, v. 31, n. 1, p. 357-369, 2013.

YIGITCANLAR, T.; O'CONNOR, K.; WESTERMAN, C. The making of knowledge cities: Melbourne's knowledge-based urban development experience. Cities, v. 25, n. 2, p. 63-72, 2008.

YIGITCANLAR, T.; SARIMIN, M. The role of universities in building prosperous knowledge cities: the Malaysian experience. Built Environment, v. 37, n. 3, p. 260-280, 2011.

YIGITCANLAR, T.; VELIBEYOGLU, K. Knowledge-based urban development: Local economic development path of Brisbane, Australia. Local Economy, v. 23, n. 3, p. 197-209, 2008.

YIGITCANLAR, T.; VELIBEYOGLU, K.; BAUM, S. (ed.). Knowledge-based Urban Development. Information Science Reference, London, 23 issue: 3, page(s): 195-207, 2008a.

YIGITCANLAR, T.; VELIBEYOGLU, K.; BAUM, S. (ed.). Creative Urban Regions. Information Science Reference, London, 2008b.

YIN, R. K. Estudo de caso: planejamento e métodos. 3. ed. Porto Alegre: Bookman, 2005.

YIGITCANLAR, T.; VELIBEYOGLU, K.; BAUM, S. (ed.). Estudo de caso: planejamento e métodos. 5. ed. Porto Alegre: Bookman, 2015.

ZHAO, P. Building knowledge city in transformation era. Asia Pacific Viewpoint, v. 51, n. 1, p. 73-90, 2010. 